\title{
Determining the optimum fixed solar-shading device for minimizing the energy consumption of a side-lit office building in a hot climate
}

\author{
Ali F. Alajmi*, Faris Aba-alkhail** and Adnan ALAnzi** \\ *Department of Mechanical Engineering, College of Technological Studies, PAAET, Kuwait \\ **Architecture Department, College of Architecture, Kuwait University \\ *Corresponding Author: af.alajmi@paaet.edu.kw
}

Submitted: 09/06/2020

Revised: $13 / 11 / 2020$

Accepted: 23/11/2020

\begin{abstract}
Buildings consume nearly $40 \%$ of the annual global energy consumption, with about $70 \%$ in hot climate regions. An efficient building design in every aspect is a crucial step towards minimizing such consumption. Windows system, including solar shading attachment, plays a pivotal role in designing a sustainable building. At the beginning, a survey of architectural firms was conducted to assess the current local practice of selecting the type and size of solar shading devices in different orientations. Regrettably, the survey outcomes did not consolidate the designers' basis for choosing such solar shading devices. Therefore, the main aim of this study is to find the optimum solar shading type and size among the three most common types (simple overhang, louvers, and overhang/sided-fins) in each façade orientation (East, West, North, and South). The manipulated design parameters comprised the overhang projection from the wall base to half of the window's height and sided-fins projection (from the wall base to half of the window's width), as well as the overhang projection's tilt angle (from $90^{\circ}$ to $135^{\circ}$ ). The considered design parameters provide 4416 design options that were handled efficiently by using the simulation-based optimization technique (SBOT).

The results showed that the overhang/sided-fins performed best in terms of reducing the total energy consumption in all orientations (13-28\%), while louvers' shading came second on all orientations by saving 10-21\% except in the East, where the simple overhang showed slightly better performance by saving $22 \%$. Recommended type and size for the solar shading in each orientation have been provided.
\end{abstract}

Keywords: Solar Shading Devices; Louvers Shading Device; Overhang/Sided-Fins Shading Device; SimulationBased Optimization Technique (SBOT); Energy Consumption.

\section{INTRODUCTION}

Buildings are the undisputed primary energy consumer in various sectors. Buildings consume nearly $40 \%$ of the annual world energy (Ameer and Krarti, 2016). Buildings also consume about $70 \%$ of the total electric energy use (main energy source) in Kuwait, which is much higher than the $40 \%$ worldwide (International Energy Agency, 2017). Kuwait accounts for 6\% of the total Middle East electric energy generation in 2017 ('BP', 2018), with the highest energy use (IEA, 2015) and second-highest carbon emission (WBCSD, 2009) per capita worldwide.

Besides the severe climatic conditions, excessive building energy use is related to nonsustainable design awareness, practices, and lack of stringent energy polices, which will have severe future consequences in terms of both economic and environmental degradation. Recent research on energy productivity for the Gulf Cooperation Council 
(GCC) countries has shed light on the importance of buildings retrofits due to benefits in energy savings, occupants' satisfaction, and fewer maintenance (Krarti, Dubey and Howarth, 2019).

Many studies have investigated the significant impact of exterior windows on energy use and cooling load of buildings. For instance, the effect of windows was found to account for $25-28 \%$ of total heat gain in residential buildings in China (Nianshan, Y. and Jiang, 2002). It also mentioned that half of the cooling load in non-residential buildings are attributed to solar heat gain. In another study, the window to wall ratio (WWR) was optimized for the low latitude region. Several options of WWR with different shading types were achieved on different orientations (Xue et al., 2019). A study of external shading horizontal louvers, with varying depths of projection, tilt angles, and spacing on south windows of four cities in Italy, was carried out using the TRNSYS calculation engine. The study proved the effectiveness of shading in cooling load and energy use reduction (Datta, 2001).

Similarly, the effect of window-to-wall ratio in different facade orientations on the reduction of both heating and cooling electricity consumption can be attained by implementing shading strategies and night ventilation on the south-oriented window (Yiwen, J. and Yi, 2006). From a different tackled angle, a simulation based on thermal and daylighting analysis has provided guidelines on the annual daylight availability ratio, WWR, glazing optical properties, orientation, climate, and shading properties at the early design stages of an office building. The authors emphasized the effect of shading on energy demand by limiting the WWR to less than $30 \%$, so as to prevent excessive daylight of the south facades in Montreal, Canada, as well as the tendency of smaller WWR on warmer climates (Tzempelikos and Athienitis, 2007). An interesting study on the effect of overhangs and louver shading devices on different façade orientations in different cities, including Cairo, Egypt, has also been conducted (Palmero-marrero and Oliveira, 2010). The authors found that thermal comfort satisfaction depends on the orientation, louver inclination angle, and window area. In particular, the louver system is optimized in the south facades to provide summer shading and solar penetration in winter. From a different perspective, the optimal type of window shading based on the quality of daylight and their related light electric energy saving for a south-oriented façade at midday on June 21 was discussed. The study showed a certain preference for vertical type shading (sided-fins) based on daylighting simulation in the similar sky conditions of Amman, Jordan, without integrating the building's total thermal response (Alzoubi and Alzoubi, 2010).

Further, the effect of shading devices on heat gain and air temperature through fenestration in hot and humid climates using building energy simulation was investigated. The study concluded that using egg-crate shading reduced discomfort hours compared with four other shading types for both ventilated and unventilated rooms (Al-tamimi, Fairuz and Fadzil, 2011). An optimization methodology that couples a genetic algorithm with Daysim and EnergyPlus simulation tools to minimize the cost for office and classroom occupancy was implemented. The study presented the effect of different solar shading parameters on the occupant's thermal and visual satisfaction on naturally ventilated spaces with electric fans in a tropical climate (Lenoir et al., 2013). Moreover, another study has separately considered the different shading configuration effects on daylighting, cooling load reduction, and simple payback period for a highrise residential building in Seoul, South Korea. The shading, daylighting, and thermal simulation were done separately and not interactively performed. The results indicated a maximum cooling energy-saving potential of $21.4 \%$, with a minimum payback period of 3-4 years (Cho et al., 2014). Another research into the impact of shading devices along with specified glazing materials on energy consumption for southern Europe showed that adding shading devices to residential buildings in addition to modest g-values (the solar coefficient factor that measures the solar energy transmittance through windows) glazing could minimize cooling load demand (Tsikaloudaki et al., 2012).

From the research studies mentioned above, window attachment and its shading devices are a crucial element of the building envelop so as to minimize building energy demand (cooling, heating, and lighting). However, most of these researches were mainly focused on a southern orientation so as to find the optimum shading device that works for summer and winter seasons. In addition, simple solar shading devices with other design parameters were investigated in different orientations. Thus, the main aim of this research is to find the most efficient type and design (dimension) of a solar shading device for each façade orientation in an extremely hot climate such as the case in the State of Kuwait. The objective will be accomplished by implementing a simulation-based optimization technique 
(SBOT) that consists of a building simulation program and an optimization algorithm. SBOT is used to investigate the possibility of minimizing the energy consumption of an office building. The manipulated design parameters are the three most common types of solar external fixed shading devices on each of the four main orientations (East, North, West, and North). The optimum solutions are constrained so as not to violate basic visual need and thermal comfort.

\section{LOCAL CLIMATE CHARACTERISTICS}

The State of Kuwait is located in one of the hottest and driest places on on the planet at the northeastern corner of the Arabian Peninsula (latitude, $29.22^{\circ} \mathrm{N}$, longitude, $47.98^{\circ} \mathrm{E}$, and $62 \mathrm{~m}$ above sea level). The upper limit of the outside temperature in Kuwait is almost always above the summer comfort dry-bulb temperature of $24-27^{\circ} \mathrm{C}$. There are a few months where the outside temperature falls within the comfort zone (November to March). In the remaining months of the year (April-October), the average temperatures are above the comfort zone; see Figure 1. At the peak of summer, the upper high temperature is always above $40^{\circ} \mathrm{C}$, with the highest recorded temperature ranging from 47 to $52^{\circ} \mathrm{C}$.

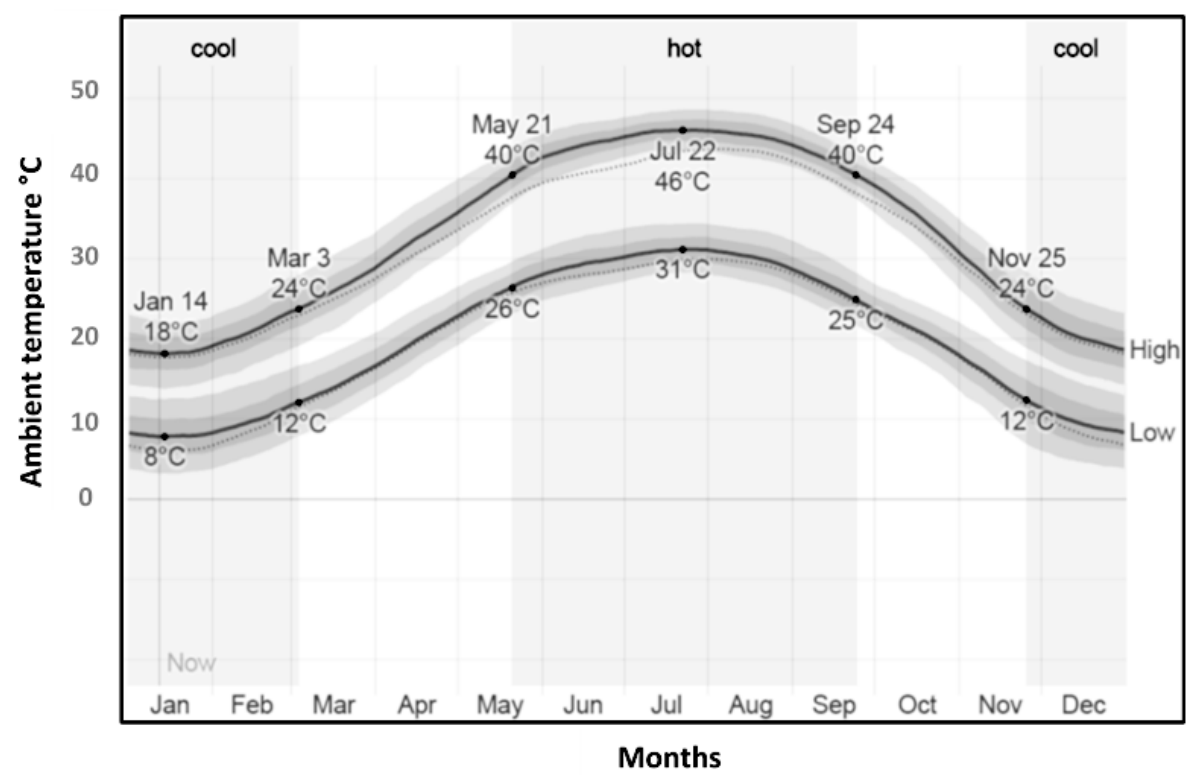

Figure 1. The daily average high (red line) and low (blue line) temperature (source: weatherspark.com, Cedar Lake Ventures).

June and July are the driest months of the year, with relatively higher wind speed and a dry bulb average temperature. The direction of the wind in Kuwait comes mainly from the Northwest and the Southeast. The transition from a high relative humidity (RH) to low RH starts in April, and the average RH falls below 40\% from June to September. March outperforms the rest of the months in maintaining an average dry bulb temperature within the comfort zone and $\mathrm{RH}$ from 30 to $70 \%$.

The rather high outside temperature is a consequent of long hours of sunshine; Kuwait is considered one of the sunniest places on earth. The monthly mean solar radiation ranges from 500 to $1042 \mathrm{~W} / \mathrm{m}^{2} /$ day, depending on the sky's level of clearance (Peel, M. C., 2007). The annual high radiation ranges between 1000 and $1100 \mathrm{Wh} / \mathrm{m}^{2}$. The global horizontal radiation increases during the summer season, especially from March to October; see Figure 2. During these months, the average direct normal and global horizontal radiation range exceeds $8000 \mathrm{Wh} / \mathrm{m}^{2}$ per day. On the other hand, both of the radiation metrics fall below $3000 \mathrm{Wh} / \mathrm{m}^{2}$ per day during the months from November to January, as shown in Figure 2. 


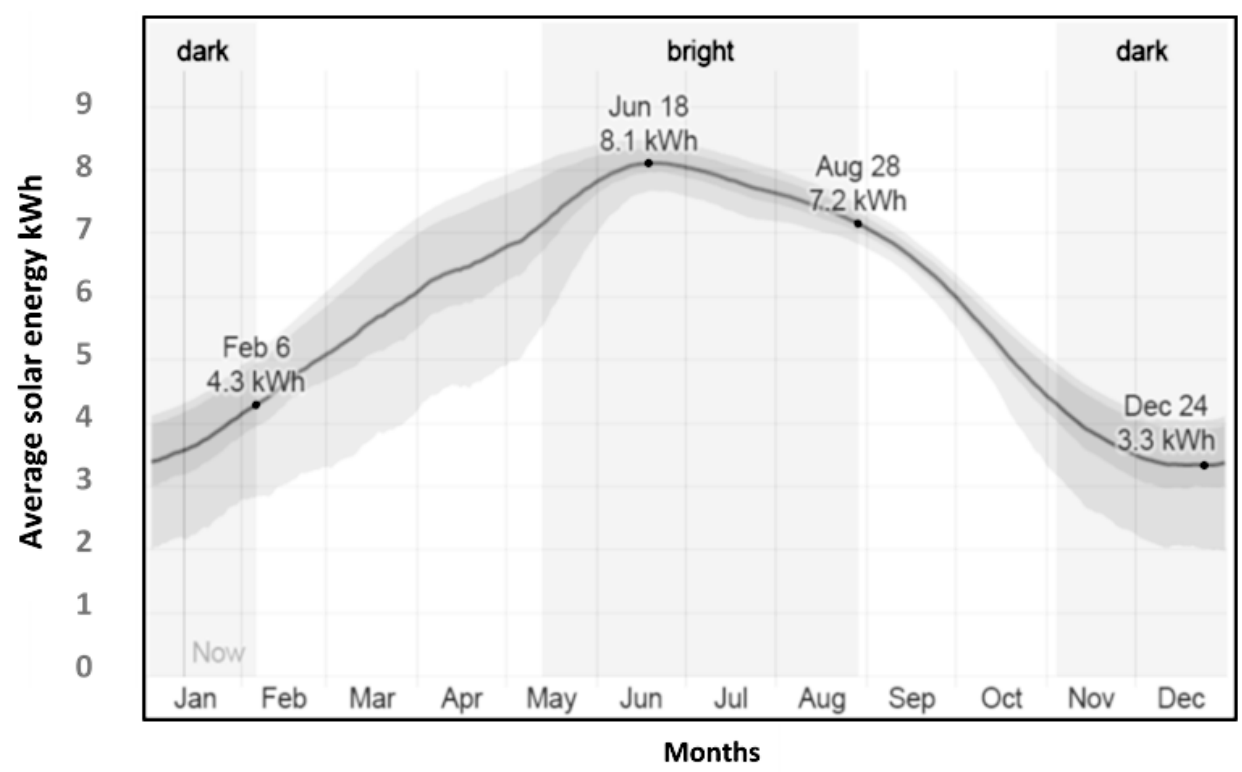

Figure 2. The average daily shortwave solar energy reaching the ground per square meter (source: weatherspark.com, Cedar Lake Ventures).

Kuwait's extremely hot and dry weather conditions also affect its inhabitants' level of comfort, as well as the overall energy performance of buildings significantly. The long summer and short winter periods should be the primary consideration during the design phases of any type of buildings, especially high-rise ones.

\section{UTILIZATION OF SOLAR SHADINGS SURVEY OF PRACTITIONERS}

In order to assess the familiarity and usability of external windows' shading devices for buildings in general and offices in particular for Kuwait, a brief questionnaire comprising of nine questions was distributed to 29 well-known local Kuwaiti architectural firms. The total number who responded to the survey was 13 out of 29 (45\%). The analysis of the survey revealed that the majority (77\%) of surveyed architects and practitioners do consider solar shading devices during the design process. Their responses to the most used shading devices were split evenly between simple overhang, louvers, and overhang/sided-fins. The survey revealed that half of the responders do not follow precise dimensions when designing overhang or fins window attachments; see Figure 3. In response to the second part of the questionnaire, more than half (57\%) of the practitioners said they would apply a simple overhang to the South-facing façade, $29 \%$ said to the West, and $14 \%$ said to the North. None of the responders would apply a simple overhang to the East, and none of them would add sided-fins to the windows facing the North. For the sided-fins window attachments, $50 \%$ said they would apply them to the South-facing windows, $38 \%$ said to the West, and $12 \%$ said to the East. Ultimately, there was no unanimity among the responders, which indicates that there is no agreed design or practice as to the most appropriate window shading devices' type and size based on the façade orientation. 
Do you consider solar shading devices during design process ?

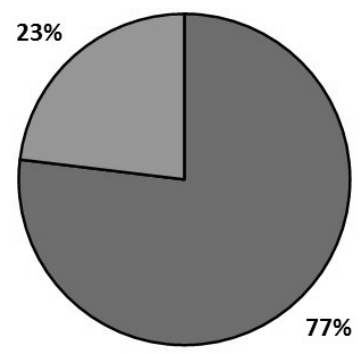

$\square$ Yes $\square$ No

What is the most common types of shading devices used for buildings in Kuwait?

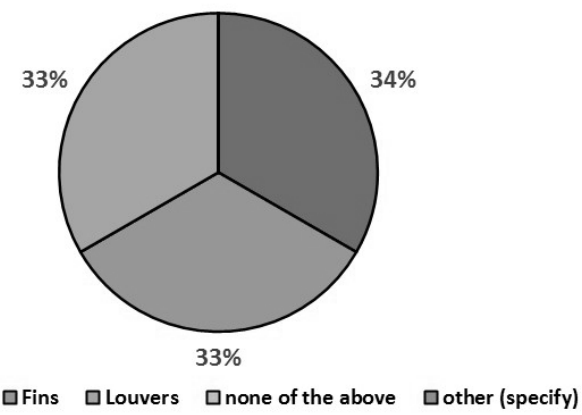

Do you follow a specific standards to design solar shading devices for buildings in Kuwait?

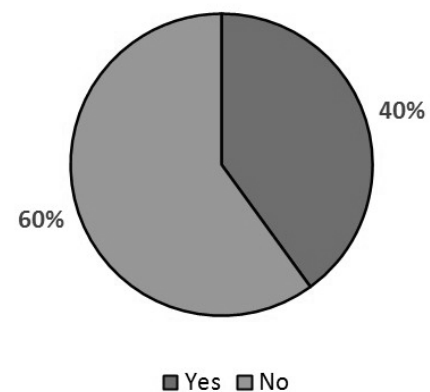

Do you follow a certain measurements when designing overhangs or fins for building in Kuwait?

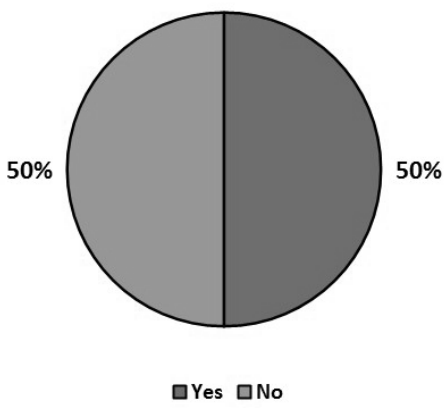

Figure 3. The surveyed responses of architects and practitioners on using solar shading devices in building facades.

Based on the survey, a simple overhang, overhang/sided-fins, and louvers are the most common types of window shading devices. Therefore, this paper will focus on these three fixed types of external window attachments.

\section{USE OF SHADINGS DEVICES ON EXISTING BUILDINGS}

Contrary to some of the survey responses, shading devices are not used in many of the newly constructed high rise buildings. A site visit to many recently built high-rise buildings in different orientations with a high glazing ratio of their facades (exceeding 50\%) found no usage of proper size and type of solar shading devices, as shown in Figure 4. This can be attributed to the following reasons. First, the Kuwaiti government highly subsidized the electricity supply (more than 95\%), which discourages clients and designers from implementing an energy-efficient strategy for highrise buildings. Second, there is a clear lack of awareness from the owner, designer, and construction practitioners over the impact of shading devices on building energy consumption, and, consequently, on the environment. Third, the use of this element of building design (shading devices) is still absent from the local energy code. 


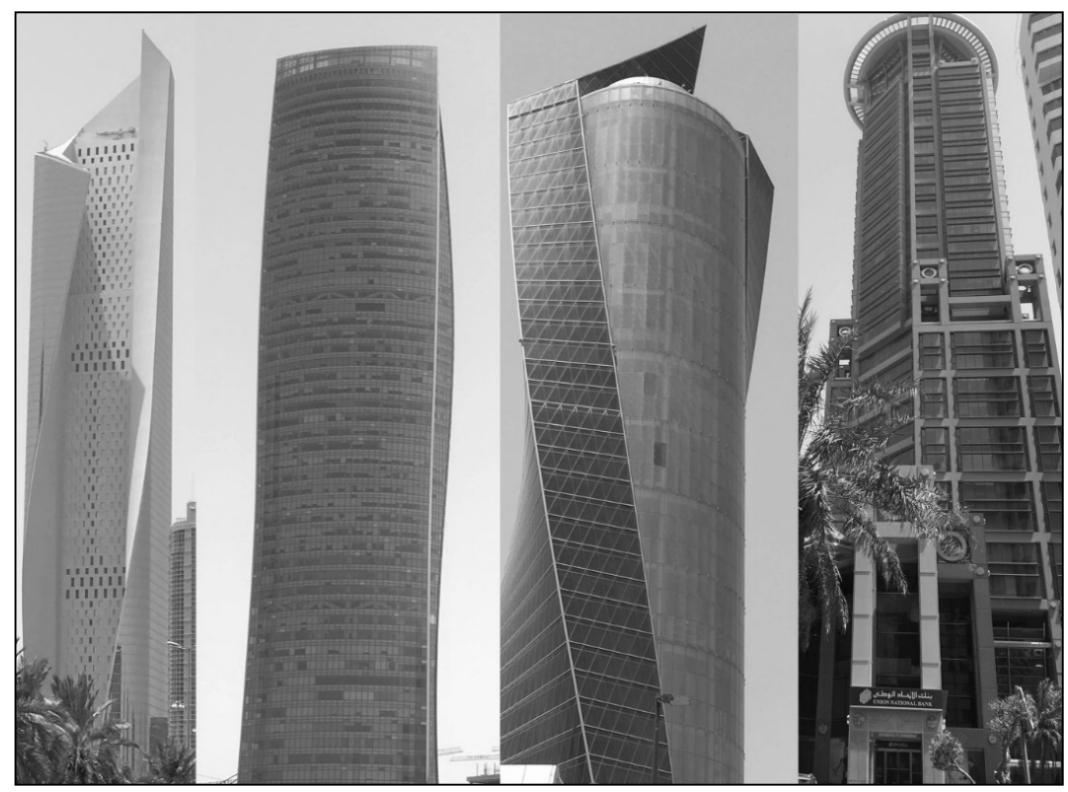

Figure 4. Newly added high-rise buildings to Kuwait City’s skyline.

\section{TYPES OF SOLAR SHADING DEVICES}

This study will focus on external fixed window devices only because they are more sustainable in such a scorching climate as in the State of Kuwait (Atzeri et al., 2014). Also, fixed shading devices have the advantages of lower capital and maintenance costs over movable ones. Conversely, other studies have proven that external movable shading devices are more efficient year-round than fixed shading devices (Manzan and Clarich, 2017).

Usually, designers and practitioners select the external window attachment type based on the sun path over these openings. For example, selecting horizontal window attachments could logically minimize the direct sunlight when the sun is in a high position at midday or during the summer season. On the other hand, vertical attachments could reduce the direct sunlight during sunrise (East) and sunset (West). This leads to the widespread use of the main types of window shading devices such as simple overhang, louvers, and simple overhang/sided-fins (please refer to question 3 in the previous section, where their configurations are illustrated in Figure 5). However, the optimum size and type of the shading devices were selected based on a simplified formula relating to the absence of simulation tools. In contrast, a variety of assistance tools that can help choose the optimum type and size of the solar shading device are readily available. An analysis of the sun path as it changes over the day, season, and building orientation can thus be performed.
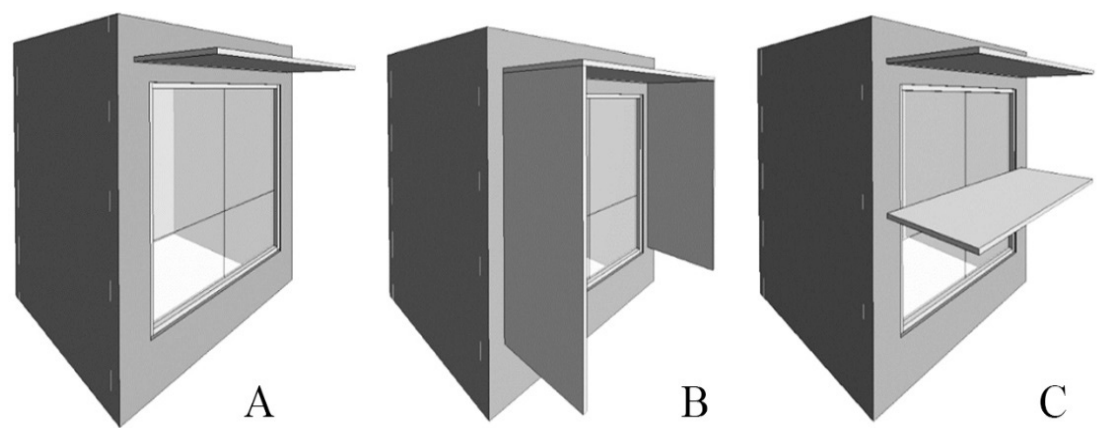

Figure 5. (A) Simple overhang. (B) Overhang/sided-fins. (C) Louvers. 


\section{METHOD AND MATERIALS}

The number of office buildings with curtain walls (fully glazed facades) both nationally and worldwide is found everywhere despite their adverse impact on energy consumption in hot climate. This paper is aimed at saving up on energy in office buildings by placing the appropriate type and size of solar shading devices in each facade orientation. Initially, a survey is conducted on leading local architectural firms (see section 3.1) to assess the level of awareness and methods followed when designing and choosing window solar attachment types. Then, the most common types of solar shading with different design parameters will be manipulated using simulation-based optimization technique (SBOT), as will be explained in the following sections, in order to find the optimal type and size of solar shading devices for each orientation.

\section{SIMULATION-BASED OPTIMIZATION TECHNIQUE (SBOT)}

Several researchers have shown that the simulation-based optimization technique (SBOT) can improve buildings' energy efficiency and indoor environment (Janeiro, 2001). In order to implement SBOT, an optimization algorithm, such as the Genetic Algorithm (GA), has to be coupled with a building simulation program such as EnergyPlus, BSIM, or DOE-2. In this research, GA was selected as the Evolutionary Algorithm (EA) for implementing the technique, while EnergyPlus was chosen as the building simulation program for calculating the required outputs.

\section{EVOLUTIONARY ALGORITHMS (GENETIC ALGORITHM)}

In natural law, the parents' chromosomes are mixed to produce a better combination for their offspring on the basis that strong genes most likely will survive into the next generations. Similarly, in artificial creations or engineering problems, a random set of chromosomes (population of possible solutions) is initiated first, which represents the initial solutions to the studied problem. Then, an evolution to that initial population takes place, using reproduction operators: selection, crossover, and mutation (Goldberg, 1989). A selection operator is invoked to create a new intermediate population of parents, where the probability for each individual to survive is in linear proportion to its fitness value. Above-average individuals are most likely to have more copies in the intermediate population, while below-average individuals will be at risk of being discarded. After the population of parents have been selected, a reproduction operator is applied to produce the new offspring. Then, a little alteration to the new chromosomes is shuffled by what is called a mutation operator.

From the above description of the technique, the reproduction looping will continue forever, forming an infinite loop. However, this process is usually terminated if one of the following four conditions is satisfied: a) a right solution is found; b) a certain number of generations or function calls have been reached; c) a set time has elapsed; or d) no improvement has been made to the solution.

In this study, the initial trails of different population sizes have been tried to ensure that the search is not trapped on local optimum solutions or run longer than needed. The trials revealed that a GA of a relatively small-size population (size 15) with a high reproduction rate, $100 \%$ crossover, and $20 \%$ mutation rate $(100 \%)$ with a fixed number of generations constitutes the most efficient combination selection, which is also in line with previous research findings (Alajmi and Wright, 2014).

\section{BUILDING SIMULATION PROGRAM (ENERGYPLUS)}

This building energy simulation program is the outcome of more than two decades of development by the US Department of Energy (Crawley et al., 2001). One of the significant features of EnergyPlus is the integration between the building's cooling loads, system, and plant. This feature allows for accurate space temperature predictions using the Predictor-Corrector Method. This method predicts the mechanical system load needed to maintain the zone air setpoint and simulates the mechanical system to determine its actual capacity. Then, it recalculates the zone air-heat balance to determine the actual zone temperature. Numerous research projects have validated the performance and 
accuracy of EnergyPlus, such as the work done by Olsen and Yan (2003). In this study, EnergyPlus calculates the heating, cooling, and lighting energy demand since the other internal load, such as the equipment set, is fixed. The indoor temperatures were set at $21^{\circ} \mathrm{C}$ and $23^{\circ} \mathrm{C}$ for the winter and summer seasons, respectively. These are the design days of summer and winter seasons in Kuwait, as per the Energy Conservation Code of Practice (MEW, 2018a).

The data of these design days, together with the design supply temperatures, are used to size the heating, ventilation, and air conditioning (HVAC) systems automatically. However, the building response to the auto-sized HVAC system is considered over a full meteorological year in order to calculate the total building energy demand accurately. In this study, the ideal load template available in EnergyPlus (i.e., "HVACTemplate: Zone: IdealLoadsAirSystem") is used to calculate the required heating and cooling demands at each calculating step for the baseline office.

\section{THE BASELINE OFFICE MODEL}

The building's geographic location and orientation have a profound effect on the solar gain by the windows and walls. The façade that receives the higher amount of radiation depends on the building's location and the season under consideration. Since the cooling load is the main electrical energy demand in hot climate regions, the focus should be on the façade that receives the maximum radiation from the sun during the long days of summer.

The studied model is a single office in a mid-floor of a multistory office building in Kuwait City. The dimensions of the representative office, used in the optimization technique to ascertain the best shading devices, are illustrated in Figure 6. The office façade has a height $(\mathrm{H})$ of 4 meters and a width $(\mathrm{W})$ of 3.2 meters. The window has a width of 2.8 meters and a height of 2.7 meters, which thus renders the window-to-wall ratio (WWR) at 59\%. A lighting sensor has been placed at the middle of the zone depth of the office, which linearly reduces the artificial light if and when sufficient daylighting penetrates the office.

The main input data to the office model according to the local energy conservation code (MEW, 2018a) is shown in Table 1.

Table 1. Input data to the studied office model.

\begin{tabular}{ll}
\hline Input items & Values \\
\hline $\begin{array}{l}\text { Occupants, equipment and } \\
\text { lighting Schedules }\end{array}$ & $1-60 \%, 7-850 \%, 8-14100 \%, 14-1650 \%, 16-1810 \%$, and $21-240 \%$ \\
\hline Activity level & set to $120 \mathrm{~W} / \mathrm{m} 2$ \\
\hline Heating and cooling setpoints & Heating: $21^{\circ} \mathrm{C}$, cooling: $23^{\circ} \mathrm{C}$ \\
\hline Clo value & set to 0.7 in summer and 1.0 in winter \\
\hline Construction: & Internal Wall: Cement Plaster, Concrete Block, Cement Plaster \\
& External Wall: Lime-Bricks, Cement Plaster, AAC Block, Cement Plaster \\
& Floor: Concrete slab, Sand, Sand Cement, Mosaic Tiles \\
& Roof: Concrete slab, Foam Concrete, Sand Screed, Water Proofing, \\
& Insulation Polystyrene, Sand Screed, Cement-Mortar, Mosaic Tiles; \\
& Ceiling: Concrete slab, Sand Screed, Water Proofing, Cement Mortar, \\
& Mosaic Tiles \\
\hline Lighting & $7 \mathrm{w} / \mathrm{m} 2$ \\
\hline Equipment & $5 \mathrm{w} / \mathrm{m} 2$ \\
\hline Infiltration & air change per hour 0.2 (ACH) for mid-floor \\
\hline Ventilation & $0.01 \mathrm{~m} 3 /$ person \\
\hline HVAC sizing factors & heating 1.25 and cooling 1.15 \\
\hline
\end{tabular}


The base model was tested for compliance with the local code and benchmarked against local data. The energy use intensity of the tested office is $246 \mathrm{kWh} / \mathrm{m}^{2}$.y. The regional benchmark of similar building functionality and activity is around $350 \mathrm{kWh} / \mathrm{m}^{2} . y$, considering that the benchmark was measured for the whole building floor area, while, in this study, only a single office in a mid-floor was measured (Alajmi, 2012).

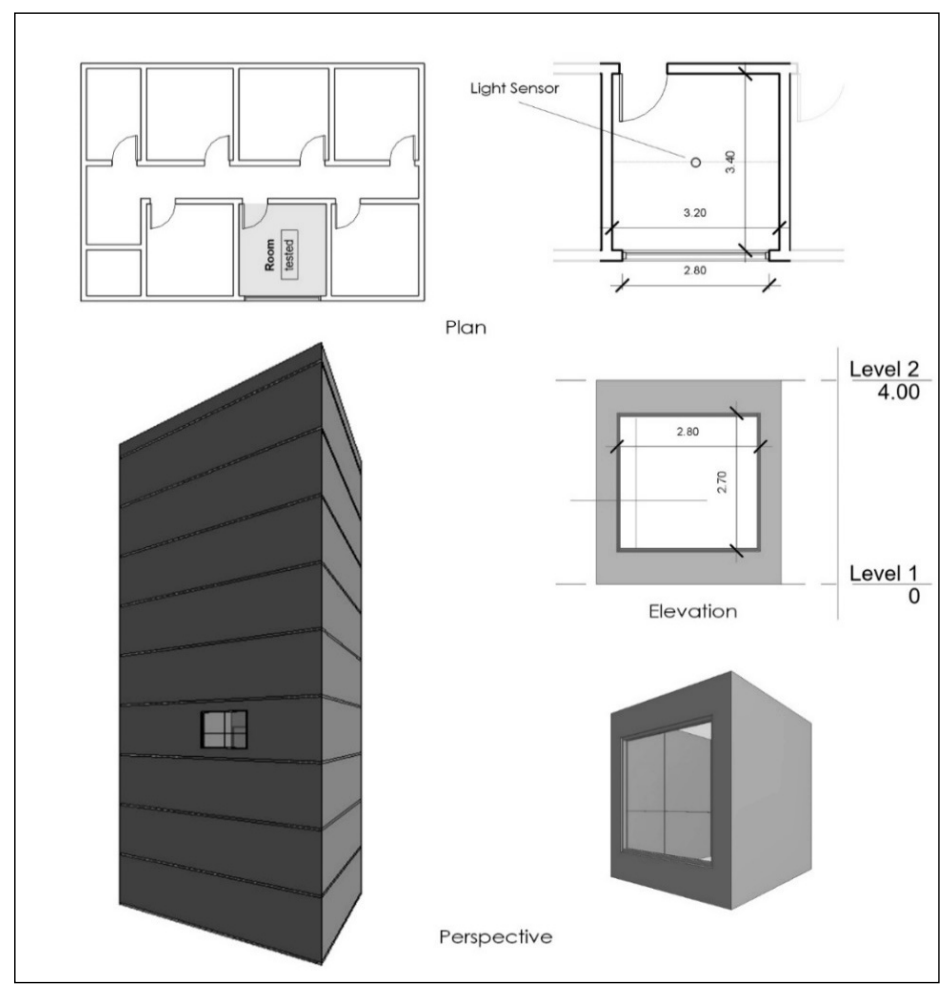

Figure 6. Studied baseline model.

\section{DESIGN PARAMETERS}

The design parameters and their bound values need to be selected carefully in any optimization issue so as not to increase the evaluated cases, which consequently increases the computational time. Thus, the chosen design parameters in this study are as follows: 1) the overhang projection, which is set to vary between zero (at the base) and half of the window's height $(\mathrm{H}) ; 2$ ) horizontal overhang tilt, which is set to range from $90^{\circ}$ to $135^{\circ}\left(90^{\circ}+45^{\circ}\right)$; 3$)$ the side-fins, which are allowed to vary up to half of the window's width (W); and 4) the louvers, which are set apart by $0.9 \mathrm{~m}$ and allowed to project incrementally in a step of $0.25 \mathrm{~m}$ from $0-1.0 \mathrm{~m}$; see Table 2 . These design parameters generate 1104 possible solutions for each orientation, making a total of 4416 possible solutions (search space). It is worth noting that the selected glazing material construction was $6 \mathrm{~mm}$-low-e clear and $12 \mathrm{~mm}$ air gap for all cases. Also, the aluminum frame and divider represent $5 \%$ of the total window area.

Table 2. Shading design parameters' values

\begin{tabular}{cccccc}
\hline No. & Variable & LB & UB & Step-size & No. of Steps \\
\hline 1 & Overhang tilt $\left({ }^{\circ}\right)$ & 90 & 135 & $5^{\circ}$ & 10 \\
\hline 2 & Overhang projection $(\mathrm{m})$ & 0 & $\mathrm{H} / 2$ & $5 \%$ & 10 \\
\hline 3 & Side-fins projection $(\mathrm{m})$ & 0 & $\mathrm{~W} / 2$ & $5 \%$ & 10 \\
\hline 4 & Two louvers $(\mathrm{m})$ & 0 & 1.0 & $0.25 \mathrm{~m}$ & 4 \\
\hline
\end{tabular}




\section{OBJECTIVES' FUNCTION AND CONSTRAINTS}

This study aims to find the best shading windows' attachment that best minimizes the annual cooling, heating, and lighting energy consumptions. The base case without shading device simulation results will be compared to the simulation results for all three types of shading devices: simple overhang, louvers, and overhang/sided-fins. It will determine how much cooling and heating loads, lighting energy, and total energy consumption will be reduced when an external solar attachment is added.

The objectives' function containing the main energy element components is given in Equations (1) and (2) as follows:

$$
\begin{aligned}
& f(x)=\left[Q_{c}(x)+Q_{h}(x)\right] / 3.6 \times 10^{6} \\
& f(y)=\left[E_{\text {lighting }}(x)\right]
\end{aligned}
$$

$Q_{c}(x)$ and $Q_{h}(x)$ represent the office annual cooling and heating energy loads in Joules $(\mathrm{J})$, respectively; the denominator is to be converted to $\mathrm{kWh}, E_{\text {Lighing }}(x)$ representing the lighting energy consumption in $\mathrm{kWh}$. The total energy consumption, taking into account the coefficient of performance (COP) of the cooling and heating systems, is 2.5 , as described in

$$
f(x, y)=f_{\min }(x)+f_{\min }(y)
$$

In order to ensure the minimum use of artificial lighting, a control sensor is placed in the middle of the office (see top-right of Figure 6) with a threshold value of 500 lux. When daylighting is available in the middle of the office at a height of $1.2 \mathrm{~m}$, the lighting control will play the role of reducing the linear use of lighting electricity. On the other hand, it will also ensure that no excessive daylighting penetrates the office, which may cause a glare discomfort. A simplified daylight glare index, which is a qualitative index primarily influenced by the light source, has been used to eliminate such a solution. Thus, in this study, the occupant is assumed to be facing $90^{\circ}$ from the side of the window. The simplified daylight glare (DGPs) index was considered as a constraint to the possible solutions with a threshold of 19, while the allowed number of hours over the course of a year should not exceed $150 \mathrm{hr}$. Its simplified form is expressed in

$$
D G P_{s}=6.22 \times 10^{-5} E_{v}+0.184
$$

\section{SBOT SETUP PROCEDURE}

Integrating a Genetic Algorithm (GA) as an optimization algorithm with the building simulation program (EnergyPlus) is a robust technique for identifying optimum solutions to many building-related efficiency problems (Tian et al., 2018). In contrast, using only a building simulation software (EnergyPlus) to arrive at the optimal or best solutions to a problem through a sensitivity analysis approach will be time-consuming.

The first step to setting up the SBOT is to prepare an EnergyPlus input file (IDF) that presents the baseline model. Then, the design parameters are kept as symbols in the IDF using the JEPlus tool developed by Java (Zhang, 2009), which allows for changing their values within their limits. This will create a project file, which will later be used by the JEPlus+EA tool to perform an optimization search using the GA (Yi Zhang, 2012).

The method used in this study is shaped for the most part by these three steps: first, creating the model in EnergyPlus program; second, adding the design parameters into the model with JEPlus; and finally, linking the project to JEPlus + EA to run the simulation and derive the optimal possible solutions; see Figure 7. 


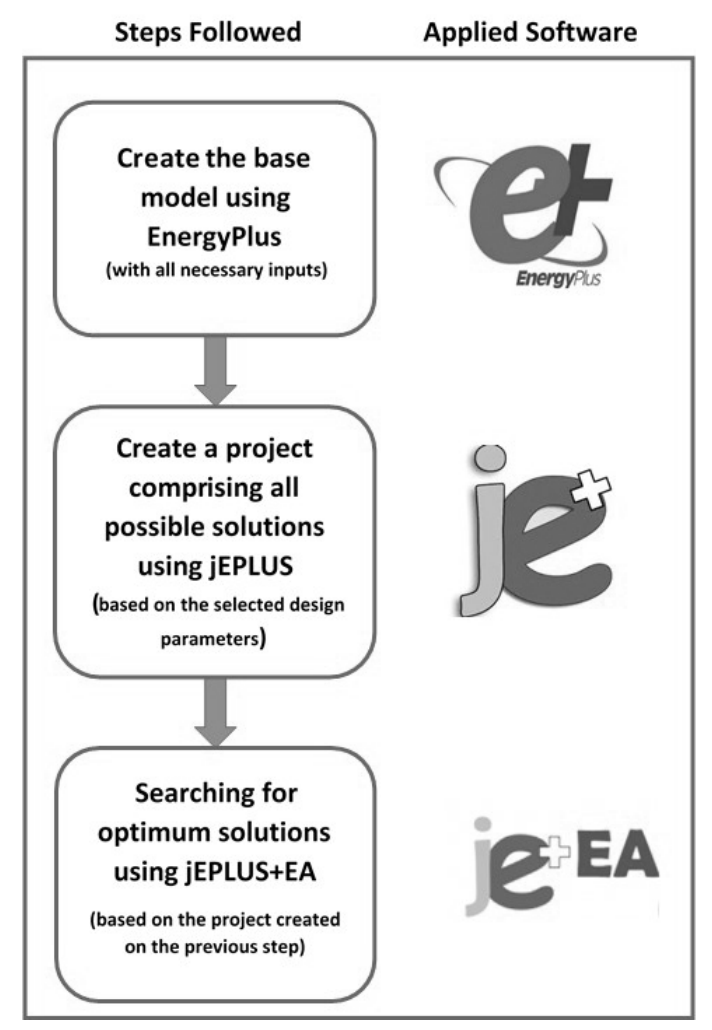

Figure 7. Simulation-based optimization technique (SBOT) procedures.

\section{RESULTS AND DISCUSSION}

The simulation-based optimization technique, SBOT, is implemented to achieve the objectives of the study. Since the GA algorithm is population-based, the results from the optimization process are expected to include various types of window attachments for each orientation. The annual energy consumption considered in evaluating the outcome of optimum solutions must not violate the constraints, the visual discomfort (glare).

In this study, the predicted mean vote (PMV) was used to assess the thermal comfort of the simulated office model. The best solution for each window attachment type at each orientation was checked with respect to the occupants' comfort. The average Predicted Mean Vote (PMV) for the hours from 7 am to $5 \mathrm{pm}$ (working hours) was predicted for summer and winter, of which none of the results violated the recommended PMV comfort range (-0.5 to 0.5).

\section{COOLING AND HEATING LOADS}

Cooling and heating loads maintain an inverse relationship along all sides of the building; if the used shading device is able to reduce the cooling load in summer, the heating load will be increased in winter, and vice versa; see Table 3. In all orientations, overhang/sided-fins are the best shading device in terms of reducing the cooling load demand, for it reduces between 18 and 32\%. On the other hand, applying the overhang/sided-fins increases the amount of heating load from 1.5 to 31 times over the base case. Notably, this has minimal consequences since the required annual amount of heating load is around 1.6\% compared to that needed for the cooling load. The louvers type is the second-best in terms of reducing the cooling load for all orientations. It reduces the cooling load between 12 and $23 \%$ and increases the heating load 1-8 times over the base case. Ultimately, the simple overhang has the least influence, which reduces the cooling load 9-24\% and increases the heating 1.5-6 times the base case. 
Table 3. Cooling and heating loads for each shading device type.

\begin{tabular}{ccccccccc}
\hline & \multicolumn{3}{c}{ Simple Overhang } & \multicolumn{2}{c}{ Louvers } & \multicolumn{2}{c}{ Overhang/sided-fins } \\
\hline \multirow{2}{*}{ East } & & $\begin{array}{c}\text { Base } \\
\text { Case } \\
(\mathbf{k W h})\end{array}$ & $\begin{array}{c}\text { Energy } \\
\text { Demand } \\
\mathbf{( k W h )}\end{array}$ & $\begin{array}{c}\text { Total } \\
\text { saving }\end{array}$ & $\begin{array}{c}\text { Energy } \\
\text { Demand } \\
\mathbf{( k W h )}\end{array}$ & $\begin{array}{c}\text { Total } \\
\text { saving }\end{array}$ & $\begin{array}{c}\text { Energy } \\
\text { Demand } \\
\mathbf{( k W h )}\end{array}$ & $\begin{array}{c}\text { Total } \\
\text { saving }\end{array}$ \\
\cline { 2 - 9 } & Cooling & 4003.9 & 3029.0 & $24 \%$ & 3072.5 & $23 \%$ & 2919.5 & $27 \%$ \\
\hline \multirow{2}{*}{ North } & Heating & 40.6 & 109.0 & $-168 \%$ & 101.7 & $-150 \%$ & 140.8 & $-247 \%$ \\
\hline \multirow{2}{*}{ West } & Cooling & 2911.0 & 2655.7 & $9 \%$ & 2549.1 & $12 \%$ & 2387.3 & $18 \%$ \\
\cline { 2 - 9 } & Heating & 133.3 & 174.6 & $-31 \%$ & 187.3 & $-41 \%$ & 208.1 & $-56 \%$ \\
\hline \multirow{2}{*}{ South } & Cooling & 3900.8 & 3184.3 & $18 \%$ & 3013.7 & $23 \%$ & 2801.8 & $28 \%$ \\
\cline { 2 - 9 } & Heating & 49.3 & 163.0 & $-230 \%$ & 116.8 & $-137 \%$ & 163.0 & $-230 \%$ \\
\hline
\end{tabular}

Since the cooling load appears to be the primary influence on energy demand, an illustration of each shading type per month is shown in Figure 8. As shown in Figure 8, the East and West orientations have the most cooling demand with similar trends. North and South orientations have less cooling demand as expected. The overhang/ sided-fins (orange bars) solar shading is the best performer compared to the other types over the summer season. The louvers (blue bars) come second in all orientations except for the East, where the simple overhang (grey bars) shows a relatively better performance.

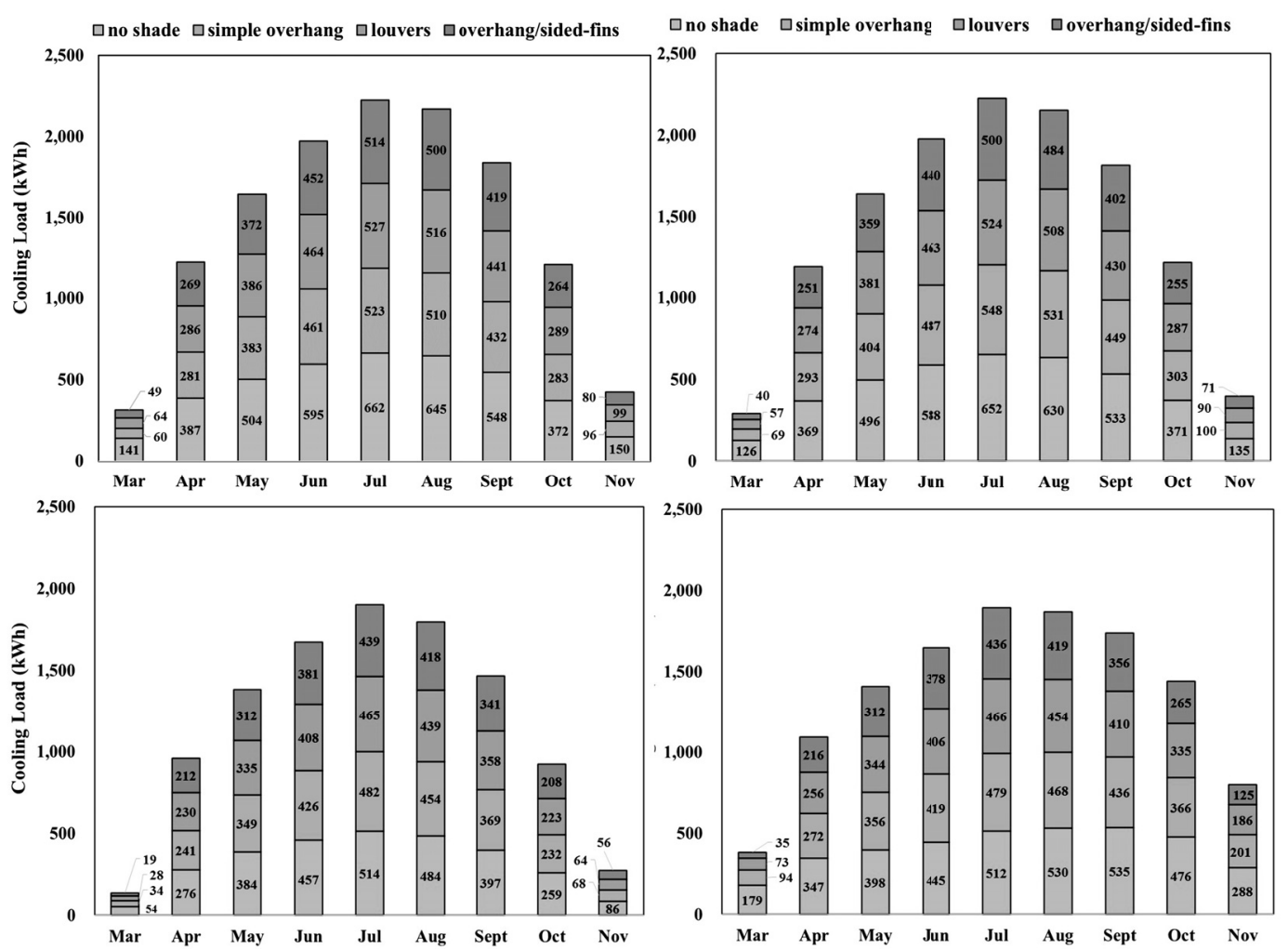

Figure 8. The cooling load for all orientations with different solar shading devices. 


\section{LIGHTING ENERGY CONSUMPTION}

In terms of lighting electric energy consumption, the base case (no shade) is the lowest since there is no obstruction to the natural lighting (daylighting), while the overhang/sided-fins are the highest. However, the difference between the four cases is small due to the cooling load's influence on finding the optimum solutions. In the East orientation, the overhang/sided-fins, simple overhang, and louvers consume $15 \%, 8 \%$, and $2 \%$, respectively, over the base case. In the North orientation, the overhang/sided-fins, simple overhang, and louvers consume $24 \%, 10 \%$, and $2 \%$, respectively. In the West orientation, the overhang/sided-fins, simple overhang, and louvers consume $19 \%, 4 \%$, and $2 \%$, respectively, while in the South, overhang/sided-fins, simple overhang, and louvers consume $11 \%, 3 \%$, and 1\%, respectively. The louvers showed the least electric lighting demand in all orientations; see Table 4. Although the lighting energy only has minimal sharing of the total amount of consumption energy, which will be discussed in the following section, it still has an implicit significance in that it has the highest daylighting availability. This aspect has a positive impact on occupants' productivity, which would be worth a deeper analysis in another study.

Table 4. Lighting demand for each shading device type.

\begin{tabular}{cccccccc}
\hline & \multicolumn{3}{c}{ Simple Overhang } & \multicolumn{2}{c}{ Louvers } & \multicolumn{2}{c}{ Overhang/sided-fins } \\
\hline & $\begin{array}{c}\text { Base } \\
\text { Case } \\
(\mathbf{k W h})\end{array}$ & $\begin{array}{c}\text { Energy } \\
\text { Demand } \\
\mathbf{( k W h )}\end{array}$ & $\begin{array}{c}\text { Total } \\
\text { saving }\end{array}$ & $\begin{array}{c}\text { Energy } \\
\text { Demand } \\
\mathbf{( k W h )}\end{array}$ & $\begin{array}{c}\text { Total } \\
\text { saving }\end{array}$ & $\begin{array}{c}\text { Energy } \\
\text { Demand } \\
\text { (kWh) }\end{array}$ & $\begin{array}{c}\text { Total } \\
\text { saving }\end{array}$ \\
\hline East & 43.3 & 46.7 & $-8 \%$ & 44.1 & $-2 \%$ & 49.9 & $-15 \%$ \\
\hline North & 43.3 & 47.8 & $-10 \%$ & 44.3 & $-2 \%$ & 53.9 & $-24 \%$ \\
\hline West & 42.9 & 44.6 & $-4 \%$ & 43.7 & $-2 \%$ & 51.0 & $-19 \%$ \\
\hline South & 42.8 & 44.0 & $-3 \%$ & 43.3 & $-1 \%$ & 47.7 & $-11 \%$ \\
\hline
\end{tabular}

\section{TOTAL ANNUAL ENERGY CONSUMPTION}

The sum total of the three main energy loads components (namely, heating, cooling load, and lighting) is vital for making a selection over the best window attachment type for each orientation of an office building. The total energy consumption for each shading device type and orientation is listed in Table 5. A coefficient of performance (COP) of 2.5 for the heating and cooling system was considered for converting the load into electrical energy consumption. As shown in Table 5, the overhang/sided-fins showed considerable saving compared to the other attachments, for it saved between 13 and $28 \%$ depending on the orientation. The overhang/sided-fins reduced energy consumption significantly in the South by $28 \%$ and considerably in the East and West by 23 and $24 \%$, respectively, while only $13 \%$ was saved in the North. The louvers shading device showed good performance as it came second on all orientations. It saved $21 \%$, $20 \%$, and $20 \%$ in the East, West, and South, respectively. Ultimately, the simple overhang had the least performance among the attachments and only showed a competitive saving in the East with $22 \%$ compared to the base case. The other orientations were $15 \%, 16 \%$, and $6 \%$ for the West, South, and North, respectively.

Table 5. Total reduction in annual energy consumption compared to the base case.

\begin{tabular}{cccccccc}
\hline & \multicolumn{2}{c}{ Simple Overhang } & \multicolumn{2}{c}{ Louvers } & \multicolumn{2}{c}{ Overhang/sided-fins } \\
\hline & $\begin{array}{c}\text { Base } \\
\text { Case } \\
(\mathbf{k W h})\end{array}$ & $\begin{array}{c}\text { Total } \\
\text { consumption } \\
\text { energy (kWh) }\end{array}$ & $\begin{array}{c}\text { Total } \\
\text { saving }\end{array}$ & $\begin{array}{c}\text { Total } \\
\text { consumption } \\
\text { energy (kWh) }\end{array}$ & $\begin{array}{c}\text { Total } \\
\text { saving }\end{array}$ & $\begin{array}{c}\text { Total } \\
\text { consumption } \\
\text { energy (kWh) }\end{array}$ & $\begin{array}{c}\text { Total } \\
\text { saving }\end{array}$ \\
\hline East & 1,661 & 1,302 & $22 \%$ & 1,314 & $21 \%$ & 1,274 & $23 \%$ \\
\hline North & 1,261 & 1,180 & $6 \%$ & 1,139 & $10 \%$ & 1,092 & $13 \%$ \\
\hline West & 1,623 & 1,384 & $15 \%$ & 1,296 & $20 \%$ & 1,237 & $24 \%$ \\
\hline South & 1,528 & 1,286 & $16 \%$ & 1,222 & $20 \%$ & 1,093 & $28 \%$ \\
\hline
\end{tabular}




\section{RECOMMENDED SIZE AND TYPE FOR SOLAR SHADING DEVICES}

The results showed that overhang/sided-fins window attachment is the best energy saver from the perspective of annual total energy demand in all orientations with a minimum saving of $13 \%$ for the North façade and maximum saving of $28 \%$ for the South façade. However, the louver showed a competitive performance in the East and West, particularly, if increased daylighting availability is an issue. Eventually, the simple overhang is only competitive in the East orientation, and it could be recommended due to its simplified construction and the material needed. Although the North façade has less benefits compared to the others with respect to reducing the energy demand, the optimal dimensions for each solar shading type are shown in * This shading dimension is perform best on these orientation.

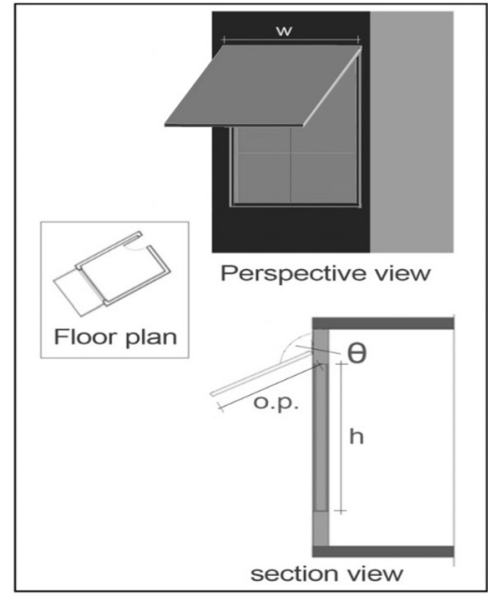

(a)

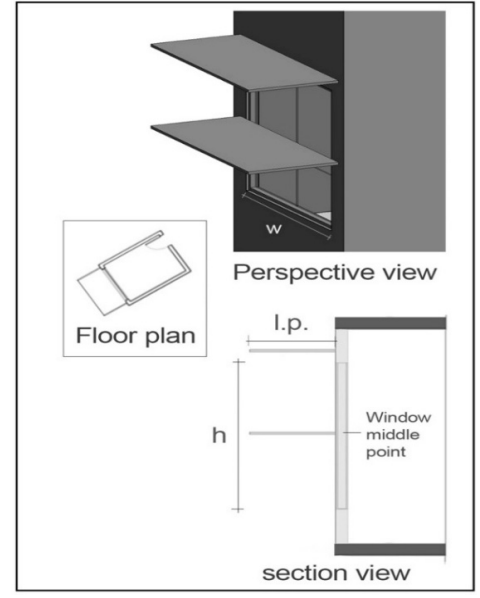

(b)

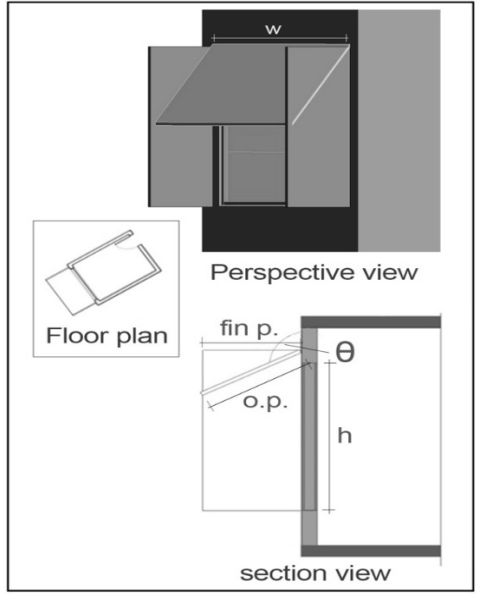

(c)

\begin{tabular}{|c|c|c|c|c|c|c|c|}
\hline & Type & $\begin{array}{c}\text { Horizontal Proj. } \\
\text { (o. p/I.p.) } \\
\text { (m) }\end{array}$ & $\begin{array}{c}\text { Ratio to } \\
\text { window height } \\
\text { (h) }\end{array}$ & $\begin{array}{c}\text { Tilt } \\
\text { Angle } \\
\left(\Theta^{\circ}\right)\end{array}$ & $\begin{array}{l}\text { Fin Proj. } \\
\text { (fin p./I.p) } \\
\text { (m) }\end{array}$ & $\begin{array}{c}\text { Ratio to } \\
\text { (w) }\end{array}$ & Orientation \\
\hline (a) & Simple overhang & 1.3 & 0.5 & 135 & - & 0.5 & East \\
\hline (b) & Louvers & 1 & 0.75 & 90 & - & - & West/South* \\
\hline (c) & Overhang/sided-fins & 1.2 & 0.45 & 130 & 1.3 & 0.45 & West/South* \\
\hline
\end{tabular}

* This shading dimension is perform best on these orientation.

Figure 9. Solar shading device dimensions for all orientations: (a) simple overhang. (b) Louvers.

(c) Overhang/sided-fins.

\section{CONCLUSIONS}

Windows' shading devices are a crucial element of buildings, particularly for curtain wall buildings. Therefore, selecting the appropriate type and size of shading elements for each orientation will minimize building energy consumption. In this study, a Simulation-based Building Optimization Technique (SBOT) is used to identify the best shading elements for reducing the energy use of an office building in Kuwait. A base model of the office building is defined using the EnergyPlus program. Different design variables of three types of external fixed window attachments (the most commonly used in Kuwait) are implemented in the model for the four main orientations (East, North, West, and North). Then, a parameterized EnergyPlus model is linked up with a Genetic Algorithm (GA) to search for the optimal solution for each orientation. The findings are extremely encouraging and can be summarized in the following points: 
- The simulation-based building optimization technique proves to be a robust method for finding the optimum solutions. In this study, the type and size of the solar shading are determined for each orientation.

- Window solar shading performs differently and competitively in terms of total annual energy savings depending on orientation.

- Cooling energy consumption was the most influential factor in choosing the best window shading device type.

- Overhang/sided-fins were the best performing window shading device for all building's facades in terms of total energy demand, and it reduces the energy consumption by $13-28 \%$.

- Simple overhang solar shading showed competitive performance on the East orientation, which was only less than the best solution by $1 \%$ but may be favored because of its simple shape of fabrication, and, hence, it is less costly.

- Louvers are found to be the second-best shading device, as it reduces the energy consumption by $10-21 \%$. Also, it can be preferable if the issue of daylighting is considered in West and South orientations.

- North orientation was the façade with the least benefit from the solar shading devices because of the nature of the sun path over the building's geographical location. However, there is a reasonable saving in energy consumption between 6 and 13\%, which needs further analysis in terms of its cost-effectiveness.

- The implemented research methodology can be tested for other climates, where different outcomes could be expected.

\section{ACKNOWLEDGMENT}

The authors would like to extend their heartfelt gratitude to Kuwait University and the College of Technological Studies for their financial and technical supports, without which this work would not have seen the light of day.

\section{REFERENCES}

Al-tamimi, N.A., Fairuz, S. \& Fadzil, S. 2011. The potential of shading devices for temperature reduction in high-rise residential buildings in the tropics. Procedia Engineering 21, pp. 273-282. doi: 10.1016/j.proeng.2011.11.2015.

Alajmi, A. 2012. Energy audit of an educational building in a hot summer climate. Energy \& Buildings Elsevier B.V., 47, pp. 122-130. doi: 10.1016/j.enbuild.2011.11.033.

Alajmi, A. \& Wright, J. 2014. Selecting the most efficient genetic algorithm sets in solving unconstrained building optimization problem, International Journal of Sustainable Built Environment, Volume 3, Issue 1, 2014, Pages 18-26, ISSN 2212-6090, https://doi.org/10.1016/j.ijsbe.2014.07.003.

Alzoubi, H.H. \& Al-zoubi, A.H. 2010. Assessment of building façade performance in terms of daylighting and the associated energy consumption in architectural spaces : Vertical and horizontal shading devices for southern exposure facades, Energy Conversion and Management. Elsevier Ltd, 51(8), pp. 1592-1599. doi: 10.1016/j.enconman.2009.08.039.

Ameer, B. \& Krarti, M. 2016. Impact of subsidization on high energy performance designs for Kuwaiti residential buildings, Energy and Buildings. Elsevier B.V., 116, pp. 249-262. doi: 10.1016/j.enbuild.2016.01.018.

Atzeri, A., Cappelletti, F. \& Gasparella, A. 2014. Internal Versus External Shading Devices Performance in Office Buildings, Energy Procedia, Volume 45, 2014, Pages 463-472, ISSN 1876-6102, https://doi.org/10.1016/j.egypro.2014.01.050.

BP. 2018. BP Statistical Review of World Energy 2018, pp. 46-48. Available at: https://www.bp.com/en/global/corporate/energyeconomics/statistical-review-of-world-energy.html.

Cedar Lake Ventures, I. (no date). The Typical Weather Anywhere on Earth. Available at: https://weatherspark.com/\%0D.

Cho, J. et al. 2014. Viability of exterior shading devices for high-rise residential buildings: Case study for cooling energy saving and economic feasibility analysis, Energy \& Buildings. Elsevier B.V., 82, pp. 771-785. doi: 10.1016/j.enbuild.2014.07.092.

Crawley, D. B. 2001. EnergyPlus : creating a new-generation building energy simulation program, 33. 
Datta, G. 2001. Effect of fixed horizontal louver shading devices on thermal perfomance of building by TRNSYS simulation, 23, pp. 497-507.

Goldberg, D.E. 1989. Genetic algorithm in search, optimization, and machine learning. 2nd editio. New York: : Addison-Wesley Publishing Company, Inc.

IEA 2015. IEA Statistics: Energy statistics for non-OECD countries. Report for the Organization for Economic Co-operation and Development. Paris.

International Energy Agency. 2017. Key world energy statistics. Available at: http://www.iea.org/statistics.

Janeiro, R. De. 2001. Architectural constraints in a generative design system: Luisa Caldas and Leslie Norford Massachusetts Institute of Technology Room 5-418 , 77 Massachusetts Avenue, pp. 1397-1404.

Krarti, M., Dubey, K. \& Howarth, N. 2019. Energy productivity analysis framework for buildings: a case study of GCC region, Energy. Elsevier Ltd, 167, pp. 1251-1265. doi: 10.1016/j.energy.2018.11.060.

Lenoir, A., Cory, Sh., Donn, M., \& Garde, F. 2013. Optimisation Methodology for the Design of Solar Shading for Thermal and Visual Comfort in Tropical Climates Piment Laboratory, University of Reunion Island, Reunion Island, France School of architecture Victoria University of Wellington, New Zealan', in Proceedings of BS2013 (ed.) 13th Conference of International Building Performance Simulation Association, Chambéry, France, August 26-28. Chambéry, France, pp. 3086-3095.

Manzan, M. \& Clarich, A. 2017. FAST energy and daylight optimization of an office with fixed and movable shading devices, Building and Environment. Elsevier Ltd, 113, pp. 175-184. doi: 10.1016/j.buildenv.2016.09.035.

MEW 2018a. MEW Energy conservation code of practice, Ministry of Electricity and Water, State of Kuwait, Mew/r-6/2018. Kuwait.

MEW 2018b. Statistical year book 2018, Ministry of Electricity and Water, State of Kuwait.

Nianshan, Y. \& Jiang, Y. (2002). Energy-saving residential buildings and ecological environment, House Science, 12.

Olsen, E.L. \& Yan, Q. 2003. Energy consumption and comfort analysis for different low-energy cooling systems in a mild climate, 35, pp. 561-571.

Palmero-marrero, A. \& Oliveira, A. 2010. Effect of louver shading devices on building energy requirements, Applied Energy. Elsevier Ltd, 87(6), pp. 2040-2049. doi: 10.1016/j.apenergy.2009.11.020.

Peel, M., Finlayson, B. \& Mcmahon, T. 2007. Updated world map of the Köppen-Geiger climate Classification. Hydrology and Earth System Sciences Discussions, European Geosciences Union, 11(5), pp.1633-1644. hal-00305098

Tian, Z., Zhang, X., Jin, X., Zhou, X., Si, B., \& Shi, X. 2018. Towards adoption of building energy simulation and optimization for passive building design: A survey and a review. Energy and Buildings, 158, 1306-1316..

Tsikaloudaki, K., Theodosiou, Th., Laskos, K. \& Bikas, D. 2012. Assessing cooling energy performance of windows for residential buildings in the Mediterranean zone, Energy Conversion and Management, Volume 64, 2012, Pages 335-343, ISSN 0196-8904, https://doi.org/10.1016/j.enconman.2012.04.020.

Tzempelikos, A. \& Athienitis, A. 2007. The impact of shading design and control on building cooling and lighting demand, (March). doi: 10.1016/j.solener.2006.06.015.

WBCSD, the W. B. C. for S. D. 2009. Energy Efficiency in Buildings: Transforming the Market. Washington, D.C.

Xue, P. Qian, Li, Q., Xie, J., Zhao, M., \& Liu, J. 2019. Optimization of window-to-wall ratio with sunshades in China low latitude region considering daylighting and energy saving requirements, Applied Energy. Elsevier, 233-234(100), pp. 62-70. ISSN 0306-2619, https://doi.org/10.1016/j.apenergy.2018.10.027.

Yiwen, J. \& Yi, J. (2006). Influence of window-wall ratio on annual energy consumption for heating and air conditioning in residential buildings, Heating', Heating, Ventilating and Air Conditioning, 36(6), pp. 1-5.

Zhang, Y. 2012. Use jEPlus as an efficient building design optimisation tool, CIBSE ASHRAE Technical Symposium, Imperial College, London UK, pp. 1-12.

Zhang, Y. 2009. Parallel energyplus and the development of a parametric, Eleventh International IBPSA Conference Glasgow, Scotland July 27-30, 2009. Glasgow, Scotland, pp. 1382-1388. 